\title{
FEATURES OF DEPRESSIVE DISORDER IN WOMAN \\ DURING PREGNANCY
}

https://doi.org/10.37096/SHDISJ-20-1.1-0004

\section{Molotokas Antonina https://orcid.org/0000-0002-0061-1528}

Abstract

Purpose of the article is to show features of depressive disorder during pregnancy and how it can be different according to various personal indicators.

Pregnancy and depression often go hand in hand. This condition affects about every tenth pregnant woman. According to recent research, sudden surges and changes in the hormonal background that accompany the entire pregnancy can really affect brain biochemistry, which in turn can lead to real clinical depression. The procedure of research registered at the women's consultation and obstetric ward and pathology department of pregnancy in Maternity hospital No. 3 (Kyiv). It lasted for 5 months. The group of pregnant women consisted of 100 people aged 18 to 42 years. Among them were 35 women in 1 trimester of pregnancy, 40 women in 2 trimester of pregnancy, 25 women in 3 trimester of pregnancy. To identify the presence and severity of depression among pregnant women, we used the following methods: Hamilton Depression Scale, Behterev Depression Questionnaire (female version).

Anxiety and depression in women during pregnancy require early detection and correction due to their significant negative impact on pregnancy, childbirth, postpartum and further psychophysical development and social adaptation of children. Different indicators of age and trimester affect the level of expression of the depressive disorder.

If woman had problems with conception or she was treated for infertility, the probability of her depression in her pregnancy increases by 10 times. Depression may be more likely to eclipse pregnancy and women who have suffered mental illness, anxiety, or depression before conception. This disorder may also occur in problematic relationships, as well as in situations where relatives have had a depression or mental illness, a woman has already had a miscarriage or her current pregnancy is a high-risk group. Depression during pregnancy has significant implications for pregnancy outcomes and maternal and child health. There is a need to identify which family, physical and mental health factors are associated with depression during pregnancy.

Key words: pregnancy, anxiety, depression, depressive disorder, research, postpartum period.

\section{Introduction}

The phenomenon of pregnancy is one of the most important factors in the formation of a specific complex of anatomical, neuro-psychological, psychological and social-psychological formations and changes of women, which are most often described in the literature by the term "maternal sphere of personality", "motherhood" (Filipp 2002). ). In this case, pregnancy in women and its phenomena are, firstly, a specific phase of gender and individual ontogeny, and secondly, a multilevel, multidimensional formation 
"SOCIALIZATION \& HUMAN DEVELOPMENT" INTERNATIONAL JOURNAL

that causes the above-mentioned specific changes in her gender status. (Filippova, 1996)

From the point of view of medical psychology, pregnancy as a specific variant of health ("third condition") (Pushkareva, 2005) is an element of the continuum "health-illness", inevitably reflected in the woman's consciousness (more precisely in the maternal sphere of woman's consciousness), and thus, reflecting in consciousness, should be combined with its internal picture - the internal (subjective) picture of pregnancy (IPP - the internal picture of pregnancy), as well as other clinical phenomena (health, illness, treatment, outcome of illness, etc.) are represented in the internal picture of disease and health (Nechaeva, 2005).

The developed classification of types of attitude to pregnancy is presented, based on the theory of relations of V.M. Myasishcheva.

Purpose of the article is to show features of depressive disorder during pregnancy and how it can be different according to various personal indicators.

\section{Theoretical background}

Depression and depressive disorders are more commonly considered in psychiatry, but lately, this disorder has been extensively studied in medical and clinical psychology, particularly in terms of the features of depressive disorders in pregnant women.

From early pregnancy to the postpartum period many important changes occur simultaneously at the biological, psychological and social levels. Adapting to these changes can put women at risk of psychological distress. The literature highlights a particularly difficult period of adaptation for first-time pregnant women (Figueiredo).
It is proved that for the development of the child the most dangerous are pathological reactions to stress and the appearance of affective pathology in the second and third trimesters of pregnancy. The effects of stress on pregnant women adversely affect the psychophysiological characteristics of infants at birth and are found to be similar to mothers addicted to smoking. Mechanisms of development of psychopathological symptomatology of non-psychotic level are conditioned by correlation of personality typology, degree of personal maturity, social and psychological factors, nature of social functioning (Pushkareva, 2017).

The most common emotional disorders encountered during gestation are anxiety and anxiety-depressive disorders. Anxiety noted by the most pregnant women is believed to be a major factor in allowing the line between women with normal physiological pregnancy and complicated pregnancy (Kolesnikov, 2012).

In this regard, obstetricians and gynecologists need effective data to help pregnant women with their current psychological status, which is largely determined by the state of the emotional sphere (Pushkareva, 2005).

The risk of developing psychosis of the gestational period in the general population is $0.1-0.25 \%$. At the same time, postpartum psychoses account for $45 \%$ $86 \%$ of all psychoses, for lactation (during the feeding period) - $10 \%-42 \%$ and psychoses of the pregnancy period - $3 \%$ $15 \%$. It is considered that the level of severe mental disorders during pregnancy is the same or even lower compared to the level of soreness outside of childbirth. Postpartum psychoses occur at a frequency of 1-2 per 1000 births (Targum, 1979) 
"SOCIALIZATION \& HUMAN DEVELOPMENT" INTERNATIONAL JOURNAL

Psychoses of pregnancy are a combined nosological group. In this case, pregnancy itself is not a cause of psychosis, but can only provoke the onset or exacerbation of already existing mental disorders. Psychotic disorders can be facilitated by various somatic pathologies that develop during this period. Psychological difficulties (family disharmony, loneliness, death of loved person) are essential (Nechaeva, 2005).

An important role in the pathogenesis of psycho-emotional disorders in women during pregnancy is played by the premorbid level of functioning of the individual, which prevails during the period of onset of pregnancy - the level of maturity of gender-role identity, which the woman has acquired by this time. It has been proven that during pregnancy there are changes in the emotional sphere of women in the direction of increasing lability. Woman becomes more sensitive and more susceptible to mood swings.

During pregnancy the subcortical structures of the brain increase the phenomenon of excitation, and in its cortex - signs of induced inhibition. Mature personality functioning correlates with better adaptation to the condition pregnancy, a more flexible adaptation to hormonal (internal) and social (external) changes during pregnancy. (Evans, Heron, 2001)

A number of foreign studies have shown that anxiety and depression in women during pregnancy require early detection and correction due to their significant negative impact on pregnancy, childbirth, postpartum and further psychophysical development and social adaptation.

Anxiety and depressive disorders in women during pregnancy can be predictors of anxiety and depressive disorders for mother mother during the first year of child's life, which adversely affects the woman's adaptation to motherhood and causes early childhood developmental abnormalities (Pushkareva, 2005).

When depressive disorders occur during pregnancy, one-third of women have depression after delivery. (McNeil, Blennow, 1988). Pre-natal depression is regarded as the most significant risk factor for the development of postpartum depression, which has a known pathological effect on the functional state of the mother, the formation of maternalinfant relationships. Depressive disorders also adversely affect the social functioning of pregnant women (Beck, 1996).

In psychiatry the interconnections and mutual influences of functional features of the central nervous system, complications of pregnancy and psychological features of the pregnant woman have been studied. Depressive disorders in women have hardly been studied in pregnancy. Dysharmonic marital relations in the family of a pregnant woman are considered by foreign authors as a significant etiological factor in the development of depressive disorders. Even with a fairly harmonious relationship of the couple, the family, which is expecting the birth of the baby, is going through the verge of serious changes, its functioning becomes unstable. As you move to a new stage in the life cycle of a family, its structure changes, new functions appear, and this affects the mental state of a pregnant woman. In turn, changes occurring in her body and psyche, largely determine the psychological situation in the family, the nature of the relationships of its members (Eydemiller, Dobryakov, Nikolskaya, 2003).

Methodology 
The study of the features of depressive disorders in pregnant women was conducted on the basis of the Department of Pathology and Women's Consultation of the Maternity Hospital No. 3 (Kyiv). The procedure of research registered at the women's consultation and obstetric ward and pathology department of pregnancy in Maternity hospital No. 3 (Kyiv). It lasted for 5 months.

To identify the presence and severity of depression among pregnant women, we used the following methods: Hamilton Depression Scale, Behterev Depression Questionnaire (female version).

The group of pregnant women surveyed consisted of 100 people aged 18 to 42 years. Among them were 35 women in 1 trimester of pregnancy, 40 women in 2 trimester of pregnancy, 25 women in 3 trimester of pregnancy.

Analyzing the anamnestic data, it was possible to identify the main negative events in patients' lives in the last few months. These include:

- conflicts with husband - 60\%;

- social and material problems $37 \%$;

- physiological changes - 26\%;

- conflicts with parents or colleagues $-23 \%$;

- death of a relative $-6 \%$;

- Other - 24\%.

\section{Results}

According to the Behterev Depression Questionnaire received the following data of depressive states in pregnant women (Fig. 1). In $40 \%$ of the surveyed pregnant women did not find depressive manifestations, which is an optimal indicator of their well-being and mood, and in $60 \%$ of women, certain characteristics of depressive states were established, which made it possible to diagnose the presence of depression. At the same time, the neurotic spectrum of depression was found in $26 \%$ of respondents who have a combination of depressed moods with anxiety for themselves and the child, are excessively emotional, pay attention to any unclear symptoms and information and therefore have an increased neurotic background.

Another $24 \%$ of pregnant women are characterized by the diagnostic uncertainty of depression, episodic manifestations of certain symptoms that may indicate a pregnant woman's predisposition to depressive experiences, but because of the lability of such conditions, the clinical form of depression cannot be unequivocally diagnosed. Provided timely provision of psychological care, such depressive symptoms will not remain. Only $10 \%$ of pregnant women surveyed have significant manifestations of depression (both physiologically and well-being). 


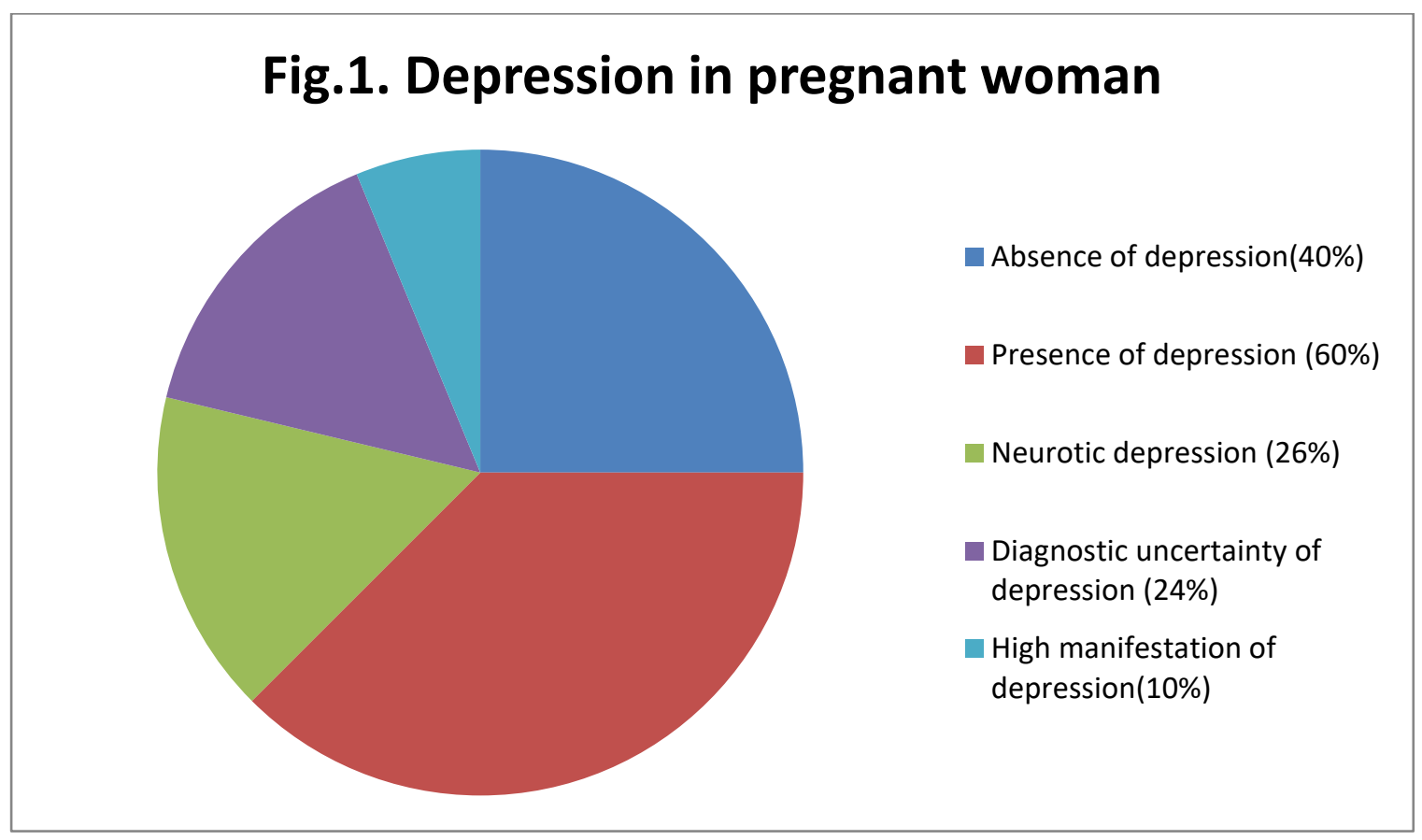

Analyzing the manifestations of depressive states in pregnant women of different ages, we found that they were absent in 9 young women under 20 years (36\%), 13 women aged 30-39 years $(37.1 \%)$ and in 18 pregnant women aged 20-29 years (Table № 1). It should be noted that two pregnant women of the oldest category (over 40 years of age) have a neurotic spectrum of depression (40\%), two have diagnostically undefined characteristics $(40 \%)$ and one pregnant woman has a clearly significant manifestation of depression (20\%).

Table 1. Depression in pregnant woman of different ages

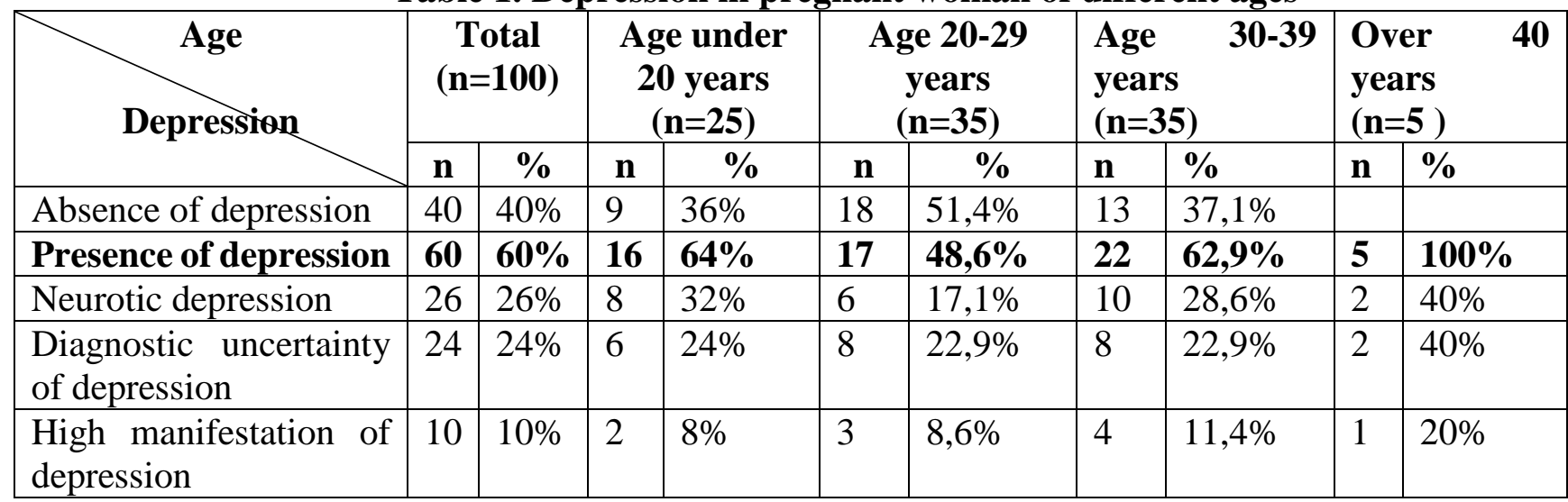

The neurotic spectrum of depression was detected in 8 pregnant women under 20 $(32 \%)$, in 6 women aged 20-29 years (17.1\%), in 10 women aged 30-39 years (28.6\%) and observed in 2 pregnant women over 40 years $(40 \%)$. Thus, the absence of depression $(36 \%)$ or its neurotic spectrum $(32 \%)$ is most characteristic for young pregnant women under 20 years, and the most seen characteristic for women aged $20-29$ is the absence of depression (51.4\%) and its neurotic form. manifestation (32\%). Pregnant women aged 30-39 years do not have depression $(37.1 \%)$, but about a third of them have a neurotic spectrum and diagnostic uncertainty about depression 
(28.6\% and $22.9 \%$ ). Pregnant women over 40 are most prone to depression - $40 \%$ of those surveyed have a neurotic spectrum of depression and diagnostic uncertainty, and $20 \%$ of them have obvious manifestations of depression.

At different trimesters of pregnancy, women also have different manifestations and symptoms of depression - its absence is most characteristic of women in the second trimester of pregnancy, when the first experiences about the health of the child decreased, and before the birth is enough time not to think about them prematurely (Table №2):

Table № 2. Depression in pregnant woman at different trimesters

\begin{tabular}{|l|l|l|l|l|l|l|}
\hline \multirow{2}{*}{ Trimester of pregnancy } & \multicolumn{2}{c|}{$\begin{array}{c}\text { I Trimester } \\
(\mathbf{n = 3 5})\end{array}$} & \multicolumn{2}{c|}{$\begin{array}{c}\text { II Trimester } \\
(\mathbf{n = 4 0 )}\end{array}$} & \multicolumn{2}{c|}{$\begin{array}{c}\text { II Trimester } \\
(\mathbf{n = 2 5})\end{array}$} \\
\cline { 2 - 8 } & $\mathbf{n}$ & $\mathbf{\%}$ & $\mathbf{n}$ & $\mathbf{\%}$ & $\mathbf{n}$ & \% \\
\hline Absence of depression & 14 & $40 \%$ & 20 & $50 \%$ & 6 & $24 \%$ \\
\hline Presence of depression & $\mathbf{2 1}$ & $\mathbf{6 0 \%}$ & $\mathbf{2 0}$ & $\mathbf{5 0 \%}$ & $\mathbf{1 9}$ & $\mathbf{7 6 \%}$ \\
\hline Neurotic depression & 9 & $25,7 \%$ & 8 & $20 \%$ & 9 & $36 \%$ \\
\hline $\begin{array}{c}\text { Diagnostic uncertainty of } \\
\text { depression }\end{array}$ & 10 & $28,6 \%$ & 8 & $20 \%$ & 6 & $24 \%$ \\
\hline $\begin{array}{l}\text { High manifestation of } \\
\text { depression }\end{array}$ & 2 & $5,7 \%$ & 4 & $10 \%$ & 4 & $16 \%$ \\
\hline
\end{tabular}

Absence of depression is characteristic of $40 \%$ of pregnant women in the 1 st trimester, half of pregnant women in the second trimester (50\%) and only $24 \%$ of women in the third trimester of pregnancy.

The neurotic spectrum of depression is found in third of pregnant women in the third trimester $(36 \%), 25.7 \%$ of women in the first trimester and $20 \%$ in the second trimester. We consider this situation quite obvious, because during the third trimester women are growing anxious and anxious about the last weeks of pregnancy, they are worried about childbirth, afraid of it, thinking about what kind of mother she will become, worried that she will not be able to understand the needs of their newborn children, etc. .

Diagnostic uncertainty of depression is found in a similar number of women in the 1st, 2 nd and 3rd trimesters of pregnancy (from $20 \%$ to 24\%). And high manifestation of depression is most seen in pregnant women in the third trimester
(16\%). In this case, the manifestations of depression are almost absent in women who are in the first trimester of pregnancy.

Therefore, women in the first trimester of pregnancy are most characterized by the absence of depression $(40 \%)$ and the diagnostic uncertainty of depression, episodic manifestations of individual symptoms (28.6\%). Half of pregnant women in the second trimester are characterized by the absence of depression, and another $20 \%$ of women have a neurotic spectrum of depressive experiences. In the third trimester, women have a clear predominance of neurotic depression (36\%), and it is in the third trimester that most women have a significant depression (16\%) associated with fear of giving birth, feelings about their baby's future.

To clarify the conclusions about the characteristic manifestations of depressive states among pregnant women, we used Hamilton's depression scale, which analyzed not only the degree of depression (from the norm (absence) to severe), but 
also some of the most expressive symptoms (Fig.№ 2, Table №2). In 58\% of pregnant women there was no depression, which indicates the norm of their psychoemotional well-being. In $24 \%$ of pregnant women have mild depressive disorder, episodic manifestations of minor symptoms of depression. Another $10 \%$ of pregnant women have moderate-grade depressive disorder, and $8 \%$ have severegrade depressive disorder.

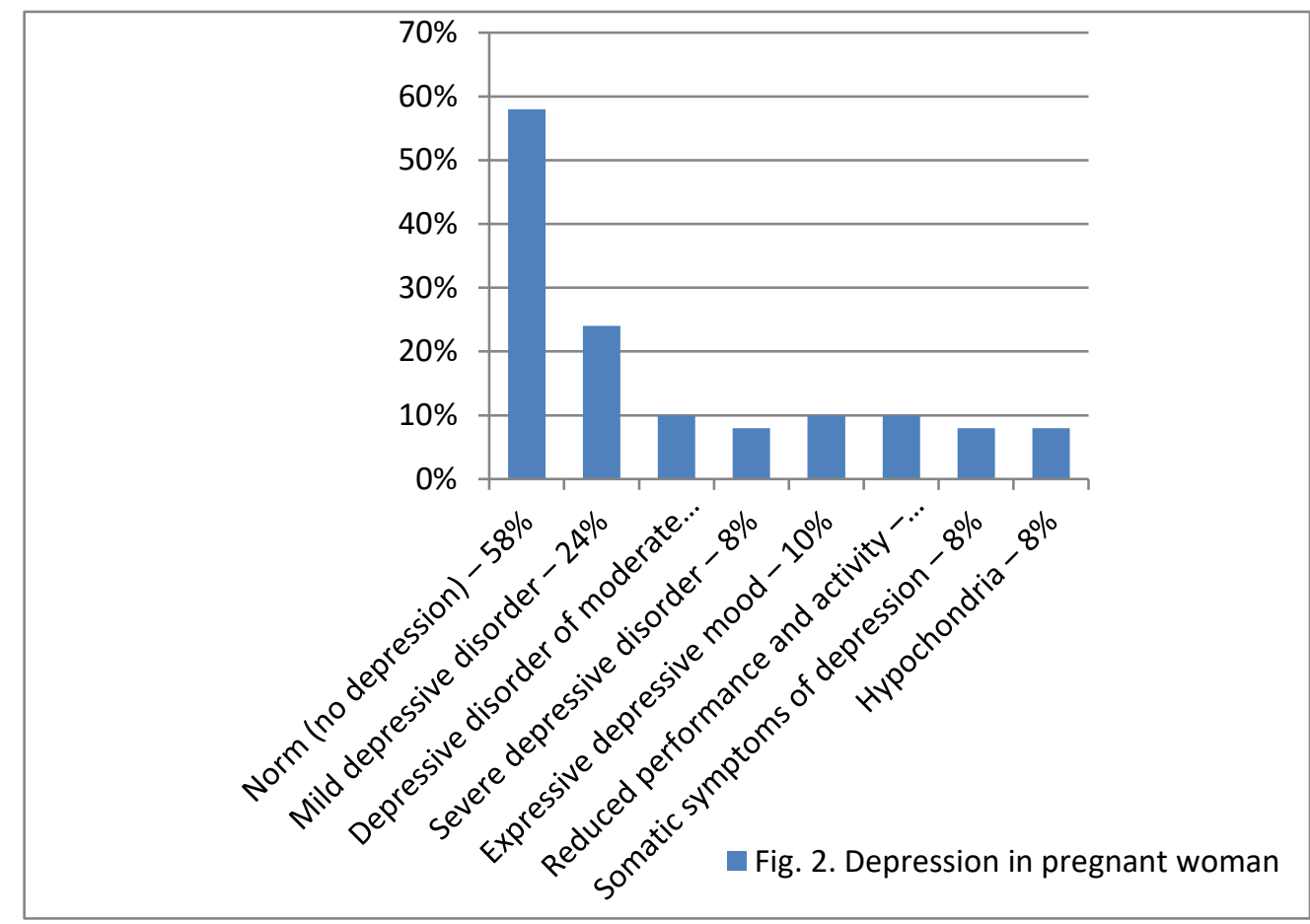

Expressive depressive mood, impaired ability to work and passivity are manifested in $10 \%$ of pregnant women, clear somatic symptoms of depression and hypochondria (excessive anxiety due to their own health) - in $8 \%$.

The following results were obtained regarding the distribution of depression in pregnant women of different ages (Table № $3)$.

Table 3. Depression in pregnant woman of different ages

\begin{tabular}{|c|c|c|c|c|c|c|c|c|c|c|}
\hline \multirow{2}{*}{$\begin{array}{l}\text { Age } \\
\text { Depression }\end{array}$} & \multicolumn{2}{|c|}{$\begin{array}{c}\text { Total } \\
(n=100)\end{array}$} & \multicolumn{2}{|c|}{$\begin{array}{l}\text { Age under } \\
20 \text { years } \\
(\mathbf{n}=25)\end{array}$} & \multicolumn{2}{|c|}{$\begin{array}{c}\text { Age } 20-29 \\
\text { years } \\
(n=35)\end{array}$} & \multicolumn{2}{|c|}{$\begin{array}{c}\text { Age } 30-39 \\
\text { years } \\
(n=35)\end{array}$} & \multicolumn{2}{|c|}{$\begin{array}{c}\text { Age over } \\
40 \text { years } \\
(n=5)\end{array}$} \\
\hline & $\mathbf{n}$ & $\%$ & $\mathbf{n}$ & $\%$ & $\mathbf{n}$ & $\%$ & $\mathrm{n}$ & $\%$ & n & $\%$ \\
\hline $\begin{array}{l}\text { Norm (no } \\
\text { depression) }\end{array}$ & 58 & $58 \%$ & 16 & $64 \%$ & 23 & $65,7 \%$ & 19 & $54,3 \%$ & & \\
\hline
\end{tabular}


"SOCIALIZATION \& HUMAN DEVELOPMENT" INTERNATIONAL JOURNAL

\begin{tabular}{|l|l|l|l|l|l|l|l|l|l|l|}
\hline $\begin{array}{l}\text { Mild } \\
\text { depressive } \\
\text { disorder }\end{array}$ & 24 & $24 \%$ & 6 & $24 \%$ & 7 & $20 \%$ & 9 & $25,7 \%$ & 2 & $40 \%$ \\
\hline $\begin{array}{l}\text { Depressive } \\
\text { disorder of } \\
\text { moderate } \\
\text { severity of } \\
\text { depression }\end{array}$ & 10 & $10 \%$ & 2 & $8 \%$ & 3 & $8,6 \%$ & 3 & $8,6 \%$ & 2 & $40 \%$ \\
\hline $\begin{array}{l}\text { Severe } \\
\text { depressive } \\
\text { disorder }\end{array}$ & 8 & $8 \%$ & 1 & $4 \%$ & 2 & $5,7 \%$ & 4 & $11,4 \%$ & 1 & $20 \%$ \\
\hline $\begin{array}{l}\text { Symptoms of } \\
\text { depression: }\end{array}$ & 10 & $10 \%$ & 1 & $4 \%$ & 4 & $11,4 \%$ & 3 & $8,6 \%$ & 2 & $40 \%$ \\
\hline $\begin{array}{l}\text { Expressive } \\
\text { depressive } \\
\text { mood }\end{array}$ & 10 & $10 \%$ & 1 & $4 \%$ & 2 & $5,7 \%$ & 4 & $11,4 \%$ & 3 & $60 \%$ \\
\hline $\begin{array}{l}\text { Reduced } \\
\text { performance } \\
\text { and activity }\end{array}$ & 8 & $8 \%$ & & & 2 & $5,7 \%$ & 2 & $5,7 \%$ & 4 & $80 \%$ \\
\hline $\begin{array}{l}\text { Somatic } \\
\text { symptoms of } \\
\text { depression }\end{array}$ & 8 & $8 \%$ & & & 2 & $5,7 \%$ & 3 & $8,6 \%$ & 3 & $60 \%$ \\
\hline Hypochondria
\end{tabular}

Pregnant women aged 20-29 years are also most characterized by the absence of depression $(65.7 \%)$, and another $20 \%$ have mild depressive disorder. At the same time $11.4 \%$ of pregnant women of this age have a distinct depressive mood (depression, helplessness, feelings of inferiority).

More than half of pregnant women aged 30-39 years have no depressive symptoms. However, $25.7 \%$ of women of this age are characterized by mild depressive disorders, and $11.4 \%$ have severe depression. Expressive depression and hypochondria (excessive anxiety due to health) are characteristic of 3 women
(8.6\%), and 4 women (11.4\%) have decreased ability to work and passivity.

Analyzing the responses of pregnant women over the age of 40 , we note the prevalence of mild to moderate depression in most of them (40\% each) and the finding of severe depression in $20 \%$ of women of this age. In this case, $80 \%$ have clear common somatic symptoms, $60 \%$ have reduced performance and lack of activity, hypochondria (excessive anxiety due to health), and $40 \%$ have a clear depressive mood.

At different trimesters of pregnancy, women exhibit a different tendency for depressive states (Table 4):

Table 4. Depression in pregnant woman at different trimesters

\begin{tabular}{|l|c|c|c|c|c|c|}
\hline \multirow{2}{*}{ Trimester } & \multicolumn{1}{c|}{$\begin{array}{c}\text { I Trimester } \\
(\mathbf{n = 3 5})\end{array}$} & \multicolumn{2}{c|}{$\begin{array}{c}\text { II Trimester } \\
(\mathbf{n = 4 0})\end{array}$} & \multicolumn{2}{c|}{$\begin{array}{c}\text { III Trimester } \\
(\mathbf{n = 2 5})\end{array}$} \\
\cline { 2 - 8 } & $\mathbf{n}$ & $\boldsymbol{\%}$ & $\mathbf{n}$ & $\boldsymbol{\%}$ & $\mathbf{n}$ & $\%$ \\
\hline Norm (no depression) & 20 & $57,1 \%$ & 24 & $60 \%$ & 14 & $56 \%$ \\
\hline Mild depressive disorder & 10 & $28,6 \%$ & 8 & $20 \%$ & 6 & $24 \%$ \\
\hline
\end{tabular}


"SOCIALIZATION \& HUMAN DEVELOPMENT" INTERNATIONAL JOURNAL

\begin{tabular}{|l|l|l|l|l|l|l|}
\hline $\begin{array}{l}\text { Depressive disorder of moderate } \\
\text { severity of depression }\end{array}$ & 4 & $11,4 \%$ & 4 & $10 \%$ & 2 & $8 \%$ \\
\hline Severe depressive disorder & $\mathbf{1}$ & $\mathbf{2 , 9 \%}$ & $\mathbf{4}$ & $\mathbf{1 0 \%}$ & $\mathbf{3}$ & $\mathbf{1 2 \%}$ \\
\hline Symptoms of depression: & & & & & & \\
\hline Expressive depressive mood & 4 & $11,4 \%$ & 4 & $10 \%$ & 2 & $8 \%$ \\
\hline Reduced performance and activity & 4 & $11,4 \%$ & 3 & $7,5 \%$ & 3 & $12 \%$ \\
\hline Somatic symptoms of depression & 1 & $2,9 \%$ & 3 & $7,5 \%$ & 4 & $16 \%$ \\
\hline Hypochondria & 3 & $8,6 \%$ & 2 & $5 \%$ & 3 & $12 \%$ \\
\hline
\end{tabular}

Most pregnant women do not have depressive symptoms $(57.1 \%$ of women in the first trimester, $60 \%$ of women in the second trimester, $56 \%$ of women in the third trimester). However, mild depressive disorder manifests in $28.6 \%$ of women in the 1 st trimester, in $20 \%$ of women in the second trimester, in $24 \%$ in the third trimester. Medium-severity depressive disorder is most characteristic of women in the 1 st trimester $(11.4 \%)$, while and third trimester $(12 \%)$.
At the same time, expressive depressive mood is observed in $11.4 \%$ of women in the 1st trimester, reduced performance and passivity are manifested in $11.4 \%$ of women in the first trimester and $12 \%$ of women in the third trimester. And the clear general somatic symptoms of depression are prevalent in women in the third trimester $(16 \%)$, also these women are most characterized by hypochondria (excessive anxiety about their health and baby's health).

Table 5.Relations between features of pregnant woman and presence of depression

\begin{tabular}{|c|c|}
\hline Features & $\begin{array}{c}\text { Pearson correlation coefficient } \\
\text { (to presence of depression) }\end{array}$ \\
\hline Age &, $385^{*}$ \\
\hline Trimester &, $419^{* *}$ \\
\hline
\end{tabular}

(** indicates significant correlation with a $99 \%$ confidence level and * indicates significant correlation with a $95 \%$ confidence level.)

\section{Discussion}

The issue of diagnosing emotional conditions in women during pregnancy is currently very acute in the field of obstetrics and psychodiagnosis. Over the last 10 years, the issues of anxiety and depressive disorders during pregnancy have been raised several times in national science, which means that there is no proper level of development of this issue. The main objective of our study was to show that the problem of depression in pregnant women is, even if it is silent and ignored. Our goal is to introduce a psychodiagnostic background in maternity hospitals, to introduce the principle of emotional involvement of a doctor in obstetric practice, to develop current studying programs for this issue.

In foreign science, the level of development of the issue of emotional problems in pregnant women is higher. There are studies that indicate that women who have a high level of anxiety or depression during pregnancy have children with different neurological problems in the future: mental retardation, delayed language development, stuttering, enuresis, fears, emotional lability. (Zabolzaeva, Kozlova, Cherny`sheva, 1998) 
"SOCIALIZATION \& HUMAN DEVELOPMENT" INTERNATIONAL JOURNAL

Also important is the fact that in most cases postpartum depression has its manifest during pregnancy, but due to inadequate diagnosis, it goes unheeded. (O’Hara, Zekoski, Philipps, 1990)

\section{Conclusion.}

The development of depressive and anxiety disorders of the non-psychotic registry may be conditioned by the specific personality characteristics of women in combination with the disturbance of the interpersonal relationships system, unreacted past stressful influences and complex social factors that lead to poor quality of life. Special attention should be paid to the experts on the occurrence and exacerbation of anxiety - depressive disorders and neurotic reactions to stress at different stages of pregnancy.

Our study and a lot of literature about medical and psychological aspects of pregnancy have shown that anxiety and depression in women during pregnancy require early detection and correction due to their significant negative impact on pregnancy, childbirth, postpartum and further psychophysical development and social adaptation of children.

Anxiety and depression disorders in women during pregnancy can be predictors of anxiety and depression disorders in Mother during the first year of motherhood and postpartum period at all.

Today there are many methods of prevention and overcoming of depressive disorders, developed within various therapeutic schools. Because depression in all its typical features is deeply individual in nature, building a strategy for its elimination and prevention requires the selection of methods that are most relevant to the psychological characteristics of each client. Formation of qualities in a person that will provide her personal stability with the effect of depressogenic factors are psycho-psychological factors relapses.

\section{References}

Bárbara Figueiredo, Ana Conde (2011). Anxiety and depression symptoms in women and men from early pregnancy to 3-months postpartum. Journal of affective disorders, No. 132, 146-157.

Beck C.T. (1996). A meta-analysis of predictors of postpartum depression. PubMed, No. 45, $297-$ 303.

Eydemiller E.G., Dobryakov I.V., Nikolskaya I.M. (2003). Semeynyiy diagnoz i semeynaya psihoterapiya: ucheb. posobie. SPb: Rech.

Evans J.(Ed.). (2001). Cohort study of depressed mood during pregnancy and after childbirth. BMJ, 323, 257.

https://doi.org/10.1136/bmj.323.730 7.257

Filippova, G.G. (Ed.). (1996). Razvitie materinskogo povedeniya $\mathrm{V}$ ontogeneze. Psihologiya segodnya.

Ezhegodnik Rossiyskogo psihologicheskogo obschestva, 3, 133.

Filippova, G.G. (Ed.). (2002). Psihologiya materinstva: ucheb. posobie. Moskva: Yzd-vo Ynstytuta Psykhoterapyy.

Kolesnikov I. (2012). Nevroticheskie depressivnyie rasstroystva $i$ semeynoe funktsionirovanie $u$ beremennyih zhenschin. Retrieved from HTTP://MPRJ.RU/ARCHIV GLOBAL/2012_5_16/NOMER/NO MER05.PHP

McNeil T.F., Blennow G. A. (1988). Prospective study of postpartum 
"SOCIALIZATION \& HUMAN DEVELOPMENT" INTERNATIONAL JOURNAL

psychoses in a highrisk group.

Relationship of birth complication and neonatal abnormality. Acta

Psychiatrica Scandinavica, 78, 613617.

Nechaeva, M.A. (2005). Psihologicheskie faktoryi ontogeneza materinskoy sferyi, vnutrenney kartinyi beremennosti i perinatalnogo razvitii. Chelyabinsk:YUrGU.

O'Hara M.W., Zekoski E.M., Philipps

L.H. (1990). Controlled prospective study of post-partum mood disorders: comparison of childbearing and nonchildbearing women. J Abnorm Psychology, 99, 3-15.

Pushkareva T.M. (2005). Poslerodovaya depressiya: rasprostranennost, klinika, dinamika. Kyiv: Psihichne zdorov'ya.
Pushkareva T.M. (2017). Algorytm skryningovoyi diagnostyky depresyvnyx ta tryvozhnodepresyvnyx rozladiv u zhinok pid chas vagitnosti ta pislya pologiv. Kyiv: Zdorov`e zhenschynu, 1, 6266.

Targum S.D. (1979). Dealing with psychosis during pregnancy. JAPhA, Vol. 9, 18-21. https://doi.org/10.1016/S01603450(15)32299-6

Zabolzaeva I.V., Kozlova M.A., Cherny`sheva L.V. (1998). Vliyanie psikhotravmiruyushhikh situaczij vo vremya beremennosti na dal nejshee razvitie rebenka. $\mathrm{SPb}$ : Akademiya mediko-soczial nogo upravleniya. 